\title{
Acute pancreatitis complicating Crohn's disease: mere coincidence or causality?
}

\author{
A Tromm, D Hüppe, G H Micklefield, U Schwegler, B May
}

\begin{abstract}
An example of acute pancreatitis developing five weeks after initial treatment with 5-aminosalicylic acid (5-ASA) and methylprednisolone for severe Crohn's disease is reported in a 37 year old female patient. She had undergone cholecystectomy for gall stones some years earlier. There was no evidence of acute or chronic pancreatitis. No morphological changes of the upper gastrointestinal tract were found except for some irregularity of the main pancreatic duct and the secondary ducts on endoscopic retrograde pancreatography. Rechallenge with 5-ASA did not induce recurrent pancreatitis or changes in pancreatic enzymes. This case report supports the concept of an association between acute pancreatitis and Crohn's disease.

(Gut 1992; 33: 1289-1291)
\end{abstract}

\section{Case report}

Acute Crohn's colitis was diagnosed endoscopically and histologically in a 37 year old woman after a symptomatic history of six months with diarrhoea and arthralgia. The patient's previous history revealed cholecystectomy for gall stones 11 years ago. Ileocolonoscopy showed severe inflammation of the colonic mucosa with ulcers and aphthous lesions in the descending, transverse, and ascending colon. Sigmoid and rectum were unaffected. Endoscopy and enteroclysis showed no ileal involvement. Endoscopy with biopsy of the upper gastrointestinal tract was carried out but no abnormalities were found.

Reduced levels of albumin $(3.2 \mathrm{~g} / \mathrm{dl})$ and haematocrit $(35 \%)$ and raised levels of alpha-1proteinase-inhibitor $(283 \mathrm{mg} / \mathrm{dl})$ and C-reactive protein $(5.7 \mathrm{mg} / \mathrm{dl})$ indicated acute inflammation.
Sixty milligrams methylprednisolone daily and $0.5 \mathrm{~g}$ 5-aminosalicylic acid (5-ASA) tid were given without any side effects. Methylprednisolone was reduced to $6 \mathrm{mg}$ every six days while 5-ASA was given at the initial dose throughout treatment. Five weeks after starting treatment with $24 \mathrm{mg}$ methylprednisolone the patient developed crampy abdominal pain and highly increased serum levels of amylase (54 IU/l; reference value $<34 \mathrm{IU} / \mathrm{l})$ and lipase (1950 IU/l; reference value $<190 \mathrm{IU} / 1$ ). Diagnosis of acute pancreatitis was established by ultrasound. The patient received parenteral nutrition for five days and improved clinically. The pathologically raised levels of amylase and lipase decreased (Figs 1, 2). Crohn's disease of the duodenum was excluded endoscopically and histologically. Endoscopic retrograde pancreaticography (Fig 3) led to a diagnosis of chronic pancreatitis I with alterations of the main pancreatic duct and the secondary pancreatic ducts. There was no evidence of other aetiological factors for acute pancreatitis for example, primary sclerosing cholangitis, alcoholism, hyperlipidaemia, hypercalcaemia, parenteral nutrition).

During the last three years six case reports ${ }^{1-6}$ have described a possible pancreatic hypersensitivity to 5-ASA. The role of methylprednisolone in inducing acute pancreatitis has also been controversially discussed. ${ }^{7}$ On account of these reports our patient was withdrawn from 5-ASA but treatment with methylprednisolone continued. After a further four weeks 5-ASA was restarted with no recurrence of pain or changes in serum enzymes (Figs 1, 2). Follow up after six months did not show any recurrence of pancreatitis during the maintenance therapy of $1.5 \mathrm{~g}$ 5-ASA and $12 \mathrm{mg}$ methylprednisolone daily.

\section{Discussion}

Pancreatitis in Crohn's disease can be induced by disease associated morphological abnormalities in the upper gastrointestinal tract (primary sclerosing cholangitis, Crohn's disease of the duodenum) or by medical treatment (azathioprine, salicylazosulphapyridine).$^{8-11}$ Nevertheless, the results of recently published papers suggest that unexplained pancreatitis associated with Crohn's disease might be an extraintestinal manifestation of the disease. ${ }^{12-14}$

Such an association, however, remains controversial. Epidemiological data about the true frequency of acute pancreatitis in Crohn's disease are not available. In the series of Seyrig ${ }^{15}$ the frequency of unexplained pancreatitis was $1.5 \%$ (five of 331), but endoscopic retrograde pancreatography (ERCP) was not performed in all patients. Analysis of our data showed four cases of acute pancreatitis in 145 observations of 114 


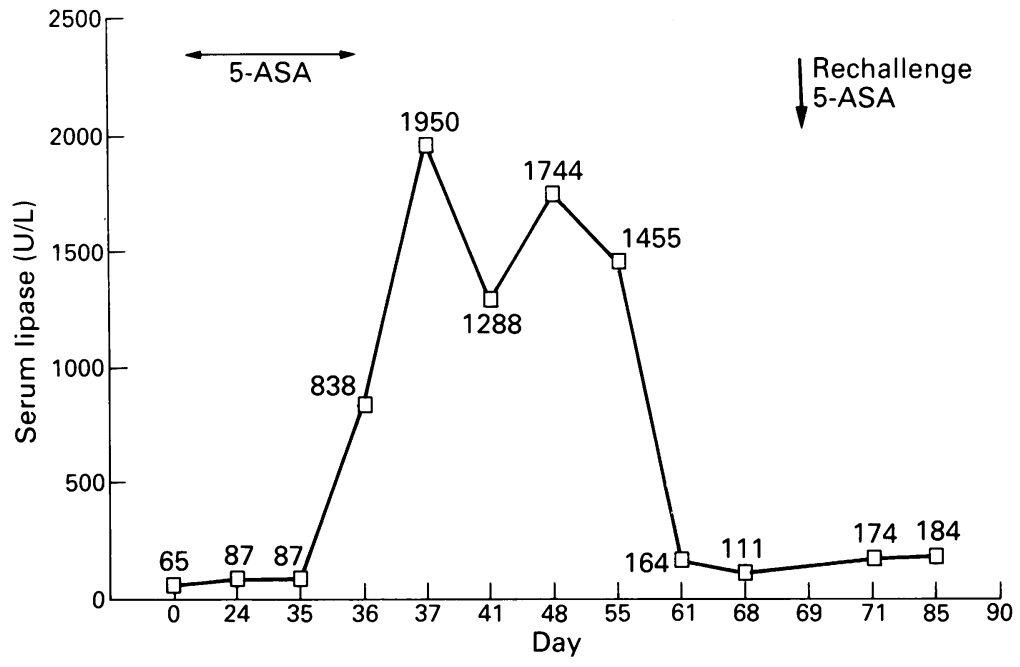

Figure 2: Levels of serum lipase (reference value $<190$ U/l). 5 ASA=5-aminosalicylic acid.

patients with Crohn's disease. ${ }^{16}$ Primary sclerosing cholangitis coincident with azathioprine therapy, pancreas divisum and treatment with sulphasalazine have been determined as the important aetiological factors in three cases, while the case of a young woman who died of a necrotic pancreatitis remains obscure. ${ }^{17}$ In our series $15 \cdot 3 \%$ of all patients showed pathologically raised levels of amylase or lipase without any clinical signs of pancreatitis or changes on ultrasound. No close relation to the disease activity or simultaneous drug treatment could be shown. ${ }^{16}$

Although the evaluation of autoantibodies to pancreatic juice is unproven, $39 \%$ of all patients examined with Crohn's disease in the series of Stöcker ${ }^{18}$ showed positive antibodies to pancreatic juice but only two of four patients who developed acute pancreatitis were antibody positive. Other studies revealed an exocrine pancrea-

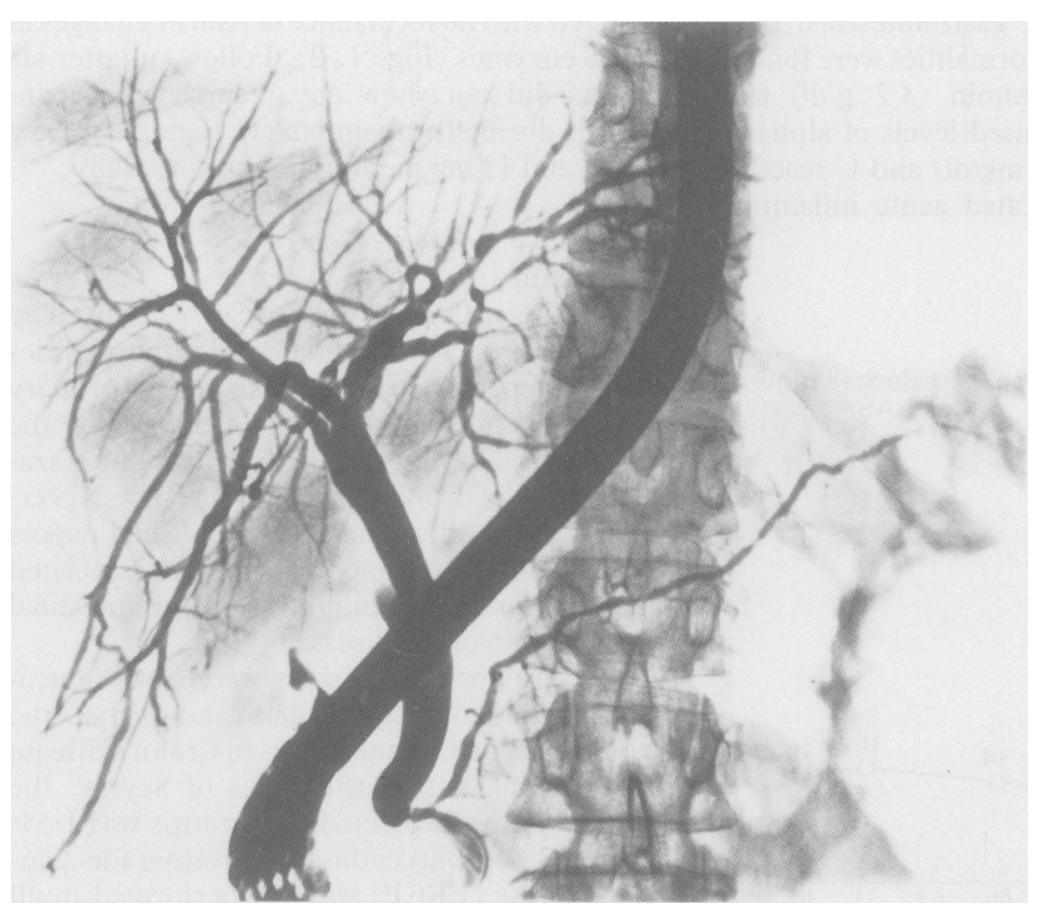

Figure 3: Irregularities of the main pancreatic duct and of the secondary ducts on endoscopic retrograde pancreatography. tic insufficiency in patients with Crohn's disease. ${ }^{19} 20$

A possible pancreatic hypersensitivity of 5-ASA is described in six previous published case reports ${ }^{1-6}$ which show the recurrence of pancreatitis after rechallenge to oral or rectal preparations of 5-ASA. Pancreatitis induced by sulphasalazine is caused by the sulphapyridine component. In contrast 5-ASA, the active therapeutic moiety of sulphasalazine, does not include sulphapyridine. The possible pathogenetic mechanism of pancreatitis induced by 5-ASA is speculative at present. An increased pancreatic duct permeability as a local effect to 5-ASA is assumed, ${ }^{6}$ but this mechanism does not explain acute pancreatitis after rectal admission of 5-ASA.

In the present case no influence of 5-ASA on rechallenge was observed. Search for potential aetiological factors might take postoperative changes after cholecystectomy into account but in our opinion the irregularities of the pancreatic ducts, which have also been described by Seyrig, ${ }^{15}$ suggest that Crohn's disease itself is the predominant factor. In this regard a pancreatic manifestation of the disease might be discussed.

In conclusion, acute pancreatitis seems to be a rare complication of Crohn's disease. Search for aetiological factors should focus attention on serious side effects of medical treatment and morphological abnormalities in the upper gastrointestinal tract. A pancreatic hypersensitivity to 5-ASA should be taken into account, but further prospective studies based on morphological, functional, epidemiological, and immunological data are required to detect whether a pancreatic manifestation of the disease exists.

1 Poldermans D, van Blankenstein M. Pancreatitis induced by disodium azodisalicylate. Am 7 Gastroenterol 1988; 83: 578 80 .

2 Deprez P, Descamps Ch, Fiasse R. Pancreatitis induced by 5-aminosalicylic acid. Lancet 1989; ii: 445.

3 Sachedina B, Saibil F, Cohen LB, Whittey J. Acute pancreatitis due to 5-aminosalicylate. Ann Intern Med 1989; 110 490-2.

4 Grimaud JC, Mailot A, Bremondy A, Thervet L, Salducci J Faut-il toujours accuser la sulfapyridine? A propos d'un cas de pancreatite aigue induite par la mesalazine. Gastroenterol Clin Biol 1989; 13: 432

5 Isaacs KL, Murphy D. Pancreatitis after rectal admission of 5-aminosalicylic acid. F Clin Gastroenterol 1990; 12: 198-9.

6 Fiorentino MT, Fracchia M, Galatola G, Barlotta A, De la Pierre $M$. Acute pancreatitis during oral 5-aminosalicylic acid therapy. Dig Dis Sci 1990; 35: 1180-2.

7 Steinberg WM, Lewis JH. Steroid-induced pancreatitis: does it really exist? Gastroenterology 1981; 81: 799-808.

8 Altman HS, Phillips G, Banks S, Klotz H. Pancreatitis associated with duodenal Crohn's disease. Am $\mathcal{F}$ Gastroenterol 1983; 78: 174-7.

9 Block MB, Genant HK, Kirsner JB. Pancreatitis as an adverse reaction to salicylazosulfapyridine. $N$ Engl $\mathcal{F}$ Med $1970 ; 282$ $380-2$.

10 Newman LH, Wellinger JR, Present DH, Aufses AH Crohn's disease of the duodenum associated with pancreatitis: A case report and review of the literature. $M$ Sinaif Med 1987; 54: 429-32.

11 Sturdevant RAL, Singleton JW, Deren JJ, Law DH, McCleery JL. Azathioprine-related pancreatitis in patients with Crohn's disease. Gastroenterology 1979; 77: 883-6.

12 Matsumoto T, Matsui T, Iida $M$, Nunoi $K$, Fujishima $M$ Acute pancreatitis as a complication of Crohn's disease. $A m \mathcal{F}$ Gastroenterol 1989; 84: 804-7.

13 Meyers S, Greenspan J, Greenstein AJ, Cohen BI, Janowit/ HD. Pancreatitis coincident with Crohn's ileocolitis. Repor of a case and review of the literature. Dis Colon Rectum 1987 30: 119-22.

14 Niemelä S, Lehtola J, Karttunen T, Lähde S. Pancreatitis in patients with chronic inflammatory bowel disease. Hepatogastroenterology 1989; 36: 175-7. 
15 Seyrig J-A, Jian R, Modigliani R, Golfain D, Florent C, Messing B, Bitoun A. Idiopathic pancreatitis associated with inflammatory bowel disease. Dig Dis Sci 1985; 30: 1121-6.

16 Tromm A, Höltmann B, Hüppe D, Schwegler U, Kuntz HD May B. Hyperamylasämie, Hyperlipasämie und Pankreatitiden bei chronisch entzündlichen Darmerkrankungen. Leber Magen Darm 1991; 1: 15-22.

17 Tromm A, Respondek M, Schwegler U, Kuntz HD, May B. Morbus Crohn assoziierte Pankreatitis. Gibt es eine neue extraintestinal Manifestation der Erkrankung? Z Gastroenterol 1990; 28: 208-10.
18 Stöcker W, Otte M, Ulrich S, Normann D, Stöcker D, Jantschek G. Autoimmunity to pancreatic juice in Crohn's disease. Results of an autoantibody screening in patients with chronic inflammatory bowel disease. Scand $\mathcal{F}$ Gastro enterol 1987; 22 (suppl 139): 41-52.

19 Angelini G, Cavallini G, Bovo P, et al. Pancreatic function in chronic inflammatory bowel disease. Int $\mathcal{F}$ Pancreatol 1988 ; 3: $185-93$.

20 Hoppe-Seyler P, Holtermann D, Gerok W. Untersuchung der exokrinen Pankreasfunktion bei M. Crohn. Z Gastroenterol 1981; 19: 570 . 